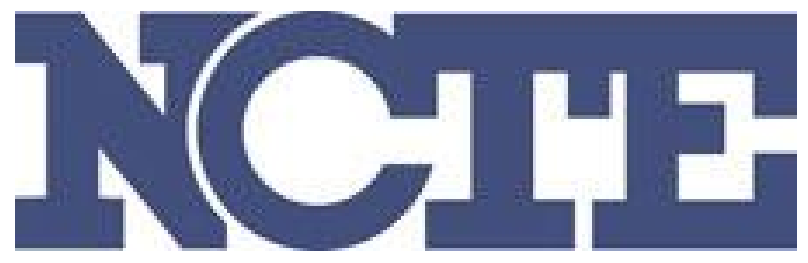

\title{
Old English Prosody: A Demurrer
}

\section{Author(s): James Sledd}

Source: College English, Vol. 31, No. 1 (Oct., 1969), pp. 71-74

Published by: National Council of Teachers of English

Stable URL: http://www.jstor.org/stable/374142

Accessed: 09-08-2016 17:30 UTC

Your use of the JSTOR archive indicates your acceptance of the Terms \& Conditions of Use, available at

http://about.jstor.org/terms

JSTOR is a not-for-profit service that helps scholars, researchers, and students discover, use, and build upon a wide range of content in a trusted digital archive. We use information technology and tools to increase productivity and facilitate new forms of scholarship. For more information about JSTOR, please contact support@jstor.org.

National Council of Teachers of English is collaborating with JSTOR to digitize, preserve and extend access to College English 


\section{Old English Prosody: A Demurrer}

As an amateur of English linguistics and medieval English poetry, I have followed the prosodic essays of Morris Halle and S. J. Keyser with considerable interest-but increasing dismay. As I have told them when they have asked me to read intended publications, their work seems to me distinctly inferior to scholarly tradition; and Keyser's most recent pronouncement, Old English Prosody (College English, Feb. 1969), strikes me as an unrelieved disaster. It is time for someone to risk flat opposition to the Cantabrigian metrists; and though I am quite inexpert in the field and can attempt (for the moment) only the briefest note, I must not keep safe and silent if no better scholar will come forward. Believing as I do, I would be wrong to say nothing while an NCTE journal (not to mention the U. S. Air Force, -whose need to scan Beowulf is well known) persists in inviting the favorable attention of a wide audience to inferior studies.

1. What some readers may tolerate as the superiority of strong minds to pedantic detail strikes me as reprehensible irresponsibility. Here are a few specimens:

a) When Keyser cites Old English lines, he neither copies, numbers, parses, nor translates them with consistent accuracy. The most superficial reader can verify this statement for himself. He will be prudent if he also verifies Keyser's quotations from other scholars, which are sometimes garbled into nonsense. ${ }^{1}$

\footnotetext{
${ }^{1}$ In his letter accepting this note for publication in College English, Mr. Ohmann as editor asked that I should either document the preceding paragraph or (preferably) omit it if it does not bear on my main objections. At the obvious risk of seeming petty, I have chosen documentation; for to me Keyser's carelessness of factual minutiae suggests impatience with the stubborn complexity of the world as it insists on being.

Miscopying. (a) By some editors of Beowulf, including Klaeber, "dissyllabic forms called for in place of contractions ... are marked by a circumflex." Keyser is inconsistent. In line 116
} (CE, Feb. 1969, p. 337) he prints hean, as Klae- ber does (though he omits the comma after büses which Klaeber, Dobbie, and Wrenn all put there); but in line 1003 (which he numbers 1004), Keyser has befléonne for Klaeber's befleonne (p. 335). (b) Without motivation that I can see, Keyser's punctuation departs from Klaeber's, Dobbie's, and Wrenn's in lines 262 (p. 336), 3 (p. 336), 38 (p. 336), 22 (p. 336), 3027 (p. 336), etc. (c) Keyser is quite careless with the editorial macrons which mark vocalic length. He blunders in lines 393 (numbered 394 on p. 336), 38 (p. 337), 1842 (p. 337), 720 (p. 340), 1537 (p. 341), etc. (d) Keyser has $\mathrm{p}$ for $\gamma$ in line 3 (p. 336), p for $\mathrm{p}$ in line 710 (p. 340), $\gamma$ for $d$ in line 36 (p. 345).

Misnumbering. Keyser numbers line 1659 as 1660 (p. 335), 1441 as 1442 (p. 344; correctly numbered on p. 341), 626 as 627 (p. 345), 2381 as 2382 (p. 345), 3102 as 3103 (p. 350), etc.

Mistaken parsing. Keyser cites two verses ( $p$. 338) which he says "exhibit an adjective inflected in the dative singular and used in an adverbial sense"; but the words which he calls adjectives are the nouns blöde and beolfre.

Mistranslation. Keyser first misprints the plural meoduscencum as meodoscencum (line 1980; p. 342) and then translates it wrongly as a singular. In line 954 (p. 347), he translates dīedum as if it were the accusative object of hafast

gefremed: "performed deeds." But diedum is dative. Clark Hall translates "brought to pass ... by thy exploits." In still a third line (3056; p. 340 ), mispunctuation leads Keyser to a faulty rendering.

Misquotation. According to Keyser (p. 347, n. 7), "The assumption of secondary stress in environments in Old English other than on the second elements of compound nouns can be traced to certain arguments by Karl Luick." Keyser goes on to quote 314.2 of Luick's Historische Grammatik. Besides assigning macrons for length to two short vowels, Keyser silently omits Luick's careful references to two earlier works by Sievers. Having also confused his following reference (to Bliss on the meter of Beowulf) by omitting four macrons from an unmarked quotation, Keyser next commits several errors in a quotation from Sievers, most notably by misprinting the digraph $æ$ as $s e$. The full list of such blunders would include specimens in quotations from Gawain and the Green Knight and from its editors and critics Tolkien and Gordon and Marie Borroff; but Robert P. Creed suffers most (p. 351). His phrase "equivalent in length (isochronous) though varying in the number of syllables" becomes "equivalent in length (isochronous) through varying the number of syllables." 
b) Keyser is shockingly careless in his factual statements. He says, for example, that "in Old English ... there were no monosyllabic words ending in a short vowel" (p. 349a). The reader who has observed be, ne, se, and pe in Keyser's own citations will be puzzled unless he remembers (as he should) that final short vowels did occur in unstressed positions. Again, Keyser can cite a number of metrically difficult lines from Beowulf (pp. 346b-347a) and announce that "all of them are emended in the standard editions," though Klaeber in his third edition (1950) mentions these same lines, cites parallels, refers to other discussions-and prints the lines without emendation. The inquisitive may refine their estimate of Keyser's accuracy by examining the identical lines in Dobbie or in Wrenn.

c) Keyser has not paid enough attention to editors or to other prosodists. As a result, some of his arguments are self-defeating. Thus he announces ( $p$. 353) that his prosody is superior to Sievers' system because the Keyserian doctrine can explain why the Gawain poet uses sprenged and rysed at the ends of lines, but in the middles of lines uses sprong and ros: " $\mathrm{S}_{3}$ must be followed somewhere to the right by a lesser stressed vowel." But Marie Borroff, whom Keyser repeatedly criticizes, observes that "the pattern $\mathrm{x} \times \mathrm{C} C$ " is "clearly exemplified" in Sir Gawain ${ }^{2}$ and a glance at the poem quickly turns up second half-lines like the following, where my italic letters mark $\mathrm{S}_{3}$ :

as hit now hat (10b)

bi $\mathrm{b}$ is burn rych (20b)

as I tryst may ( $380 \mathrm{~b}$ )

3if I my3t last (1061b)

and yow god post (1245b)

to pe derk ny3t (1887b)

If " $S_{3}$ must be followed somewhere to the right by a lesser stressed vowel," Keyser must say of Gawain precisely what he prides himself on not saying

2 Marie Borroff, Sir Gawain and the Green Knight (New Haven, 1962), 189. about Beowulf: either a corrupt manuscript must be emended, or the poet was metrically incompetent.

Keyser's discussion of Beowulf 2714 is equally unfortunate. He prints the line without the editors' inflectional vowel

in bealonið(e), which they include to make the second half-line fit Sievers' Type E. But the editors tell us (though Keyser does not) that at this point the manuscript now shows only beal and that for the rest of the word we must go to the two Thorkelin transcripts, which were made before the edges of the manuscript had crumbled so badly. According to Dobbie, who cites other instances, "the final $-i$ in the reading bealo nið $i$ of transcript $\mathrm{B}$ undoubtedly reflects an $-e$ in the MS.," since "in the hand of the second scribe, the heavy vertical stroke of $e$ may easily be mistaken for an $i$ if the letter is at all obscure." 3 Keyser's contribution is thus to use his prosodic theory to dismiss the correct reading, which Sievers' prosody, on the other hand, leads one to accept.

2. Superiority to pedantry should not imply superiority to logic, but I at least find Keyser's reasoning sometimes impossible to follow.

a) According to Marie Borroff in her discussion of Sir Gawain,

In view of the treatment of Romance stem-suffix derivatives in intralinear position, it may be concluded that the suffixaccent they receive in rhyme was not used in the spoken language. Similar artificial shift of accent to the suffix in rhyme is exemplified in the wheels for native derivatives, e.g., talkyng "Schal lerne of luf-talkyng" and lazande in 1207 "Wyth lyppez smal lazande." (p. 163)

Rejecting this traditional doctrine of poetic license, Keyser finds in the same phenomena a proof of the poet's artistic manipulation of the language as it really was:

Now what is of special interest in GGK

3 Elliott Van Kirk Dobbic, ed., Beowulf and Judith (New York, 1953), "Notes on Beowulf," $2714,2464$. 
is that the rule for stress assignment correlates with the two metrical systems used in the poem. That is, the alliterative verse of the stanzas exhibits words whose stress placement is assigned by the Germanic stress rule. The rhymed syllabotonic verses of the wheel, on the other hand, exhibit stress placement assigned by the Romance stress rule. Thus, far from entailing a violation of the linguistic givens, the Gawain-poet is manipulating the linguistic givens of his language in a striking and artful fashion. In particular, he is suiting the stress rules of his language to the metrical systems which each rule is naturally associated with; the Germanic with the native verse, the Romance with the more highly constrained, nonnative verse tradition. (CE, Feb. 1969, p. 355)

Keyser's suggestion, I should think, is more likely to appeal to an acrostician than to a poet, and he might have had some difficulty in explaining it at the Christmas games in Camelot. Why is there no violation of "linguistic givens" when the poet gives the same word now Romance stress and now Germanic, though the word itself must be either Germanic or Romance (the "two classes" that Keyser recognizes)? Did lovers make out as well as they do now if they gave final stress to luf-talkyng? And why should Romance rhyming induce Romance stress although Romance meter has no such effect? (Quite a number of Romance dissyllables with tense second vowels have initial stress in the wheelsseruaunt, for example, with initial stress within the line at 1240 , but with final stress in rhyme at 1845.) The prosaic would assume that even a quite unartful poet, if he set himself to make masculine rhymes with plurisyllables, would give them final stress.

b) But the notion of poetic license is an abomination for Keyser, as it must always be for linguistic critics and historians of stress, who want the structure of language to determine the structure of poetry, so that the structure of poetry will lead them to the structure of language. Keyser argues his position (pp.
331-2) by silently equating the acceptance of limited, conventional deviation from "linguistic givens" with the very different principle that anything goes, that any and all deviations are acceptable. The argument is transparently fallacious; and the least reading or reflection will show that deviation from "linguistic givens" is part of the fun in a good deal of poetry, from Spenser's experiments in his Calendar and Faerie Queene through Byron's rhymes in Don Juan to spur-of-the moment foolishness like

\section{She is, but hadn't ought to be} In Heaven yclept Euphrosyne.

It simply cannot be maintained, as a general principle, that poets do not play tricks with the language, for the sake of their meter or for other reasons; and if the general principle cannot be maintained, then individual instances must be examined individually. Which is where we were before.

3. The ultimate objection to Keyser's prosody is also an objection to bad reasoning, but so powerful an objection that it deserves separate statement. It is a weakness of Sievers' theory, Keyser says (p. 350b), that "an eight syllable line is the minimal line" that it allows; and Keyser makes it an advantage of his own system that it can easily accommodate half-lines like secg betsta. Indeed it can. It can accommodate "Ride a cockhorse to Banbury Cross" (and other things that would have made Caedmon gasp and stare), and so far as I can tell it could accommodate as perfectly metrical such nonsense-lines as these:

$$
\begin{aligned}
& \text { bāt bàt bātes } \\
& \text { bāt bātes bāt } \\
& \text { bāt bàt bātes bāt }
\end{aligned}
$$

earfoðhwile earfoðhwile

$$
\text { earfoðhwile earfoðhwīe }
$$

caldum clommum caldum clommum caldum clommum caldum clommum

That is precisely what is wrong with 
Keyser's prosody: it is altogether too accommodating. Keyser provides no evidence that all of the many different patterns which his rules set up as equally metrical can actually be exemplified in Germanic verse. Where are the monosyllabic half-lines, the lines of four syllables or five, which the system tells us we should find in Beowulf? If they cannot be produced, where is the explanation for their absence? And even if appeal should be made to the incompleteness of our poetic records, what explanation can make it plausible that the one long

\section{Reply}

The CRITICISMS of my "Old English Prosody" (OEP) that are made by J. Sledd in "Old English Prosody: A Demurrer" are of two sorts, theoretical and factual. I shall deal with each in turn, beginning with the former.

It was pointed out and documented in OEP that many prosodists have made use of a principle which allows one to alter the linguistic givens of a language in order to enable a particular metrical pattern to be realized. Marie Borroff speaks of an "artificial shift of accent"; Ten Brink of a "legitimate shifting of the accent for the sake of the metre"; and Sledd of "poetic license." This principle as stated fails to distinguish between possible and impossible deviations. It is my contention that whenever a poet deviates from the normal linguistic givens of his language, the deviation will always be constrained by the sytem of rules of the language which he possesses and no deviation will ever go outside those rules. Thus if one speaks of "artificial shift of accent to the suffix" in the wheels of Gawain, one fails to specify whether the artificial shift goes beyond the system of rules possessed by the poet, or whether-as I believe-the shift represents a possible re-assignment of stress in accordance with the very same rules of stress placement that the poet normally uses.

Sledd says, "Keyser argues his position syllable of bat should be metrically equivalent to the eight syllables of caldum clommum caldum clommum, as in my nonsense verses?

Those are questions that leave me gasping; until they are answered, or their irrelevance demonstrated, I must conclude that Keyser's theory is what I have called it, an unrelieved disaster. If I am wrong, tomorrow is All Fools' Day.

James SLedd

The University of Texas at Austin March 31, 1969

(pp. 331-32) by silently equating the acceptance of limited, conventional deviation from "linguistic givens" with the very different principle that anything goes, that any and all deviations are acceptable." This remark makes it appear that there exists in the literature a statement of the conventions that determine which deviations from linguistic givens are admissable and which are not. Such a statement has never been given. All that exists is lists of examples from which one cannot help but conclude that indeed anything goes, for the only limitation on what is included in these lists is what appears in the corpus, and the lists would automatically be extended if the corpus were to be augmented by the discovery, say, of hitherto unknown texts.

In launching the slogan of "no violation of linguistic givens for the sake of the meter" Halle and I were attempting to specify the limitations under which deviations were allowed. We argued that during the time of the Gawain poet English possessed two stress rules, a Germanic stress rule inherited from Old English and a Romance stress rule, introduced into the language as a result of the massive influx of Romance words after the Conquest. By the time of the Gawain poet both rules were still in the language and which rule governed the stress in a given word was a function of whether that word was marked native 